\title{
Motivos: uma análise da prova de redação do Enem
}

\section{Nathalia Melati ${ }^{1}$}

$\mathrm{O}$

ensino da produção textual é um desafio comum aos professores de Língua Portuguesa. Para o Ensino Médio, é ainda mais latente a exigência de capacitar os alunos para que possam realizar as mais diversas provas previstas no início da vida adulta. Às vésperas do vestibular e do Enem (Exame Nacional do Ensino Médio), esses estudantes compreendem as características essenciais de um texto, inclusive de uma produção argumentativa. Falta-lhes, no entanto, a compreensão do que diferencia uma redação excelente de uma mediana numa perspectiva avaliativa e, sobretudo, persuasiva.

Como profissionais da língua, há uma tendência natural de o professor corrigir apenas os erros presentes na superfície do texto, sem levar em conta a propriedade maior de um discurso: agir sobre o mundo. Escrevemos com o objetivo de criar um texto que possa causar efeito, em momentos e locais diferentes (BAZERMAN, 2015). Isso significa que, ao produzir texto, esperamos uma reação a ele. Ao escrever um comentário reclamando de qualquer produto nas redes sociais, espera-se, claramente, que o responsável pela produção desse produto se manifeste e resolva o problema.

Isso é o que Bazerman (2015) estabelece como o motivo do texto; para a retórica clássica, essa motivação está na busca do orador em mover um auditório a aceitar uma determinada opinião sobre um assunto controverso. Dessa forma, há situações específicas de uso da língua em que a motivação

$1 \quad$ Doutoranda em Língua Portuguesa pela PUC-SP; Mestre em Língua Portuguesa pela PUC-SP; Membro do Grupo ERA; Bolsista CAPES. 
é clara. Preencher um formulário para renovação de qualquer documento é motivado pelo desejo de se renovar o documento. Assim, o leitor desse texto (auditório) precisa compreender as informações ali presentes para reagir ao texto e realizar a renovação.

Muitas vezes, no ensino de produção textual, a força intrínseca das palavras é ofuscada diante de aspectos gramaticais e pouco retóricos. A realidade, no entanto, é que o texto, ainda que formalmente correto, pode não persuadir os examinadores na intensidade do desejo do orador, uma vez que o texto parece descolado da realidade. É uma produção que não indica o seu autor, seu leitor ou a sua motivação.

O ensino médio recebe alunos que já completaram, pelo menos, nove anos de educação formal, e, no mínimo, mil horas de aulas de Língua Portuguesa. O texto, para eles, já é um produto final de um longo processo de escrita e, assim, termina num ponto final que não leva em conta o ecoar do discurso. Não é viável para um professor ensinar a produção de texto a partir da estaca zero. Parte do desafio, pois, consiste em como demonstrar para esses alunos que a noção de erro não está na escrita do texto, mas no processo que se inicia com a leitura da proposta de redação.

Com o objetivo de contribuir para o debate sobre práticas em sala de aula, este capítulo parte da perspectiva retórica para compreender a leitura crítica das propostas de redação do Enem como um possível instrumento auxiliar no desenvolvimento de dois itens essenciais: a motivação do autor da redação do Enem; e a definição dos papeis do autor e leitor dessa redação.

É necessário fazer, neste momento, uma ressalva. Assim como muitos outros, este texto tem como motivação contribuir para a prática pedagógica do ensino de Língua Portuguesa. Acreditamos que cada texto produzido sobre a prática docente se insere em um longo diálogo entre professores e pesquisadores. Nesse sentido, cada e toda pesquisa com ênfase em educação colabora, a seu modo, para o aprimoramento da educação e para o consequente aprimoramento humano de cada um dos alunos que frequentam as salas de aula deste país tão ricamente repleto de contrastes e de paixões edificantes.

\section{A importância da motivação}

De acordo com Bazerman (2015, p. 21), "a retórica é a arte prática reflexiva do enunciado estratégico em contexto do ponto de vista dos participantes, tanto falantes quanto ouvintes, escritores e leitores". Isso 
significa que a função da retórica é pensar como podemos usar as palavras de maneira eficaz para conseguirmos alcançar objetivos específicos, uma vez que a linguagem humana é baseada na interação em contexto. Isto é, não produzimos discursos sem propósitos ou deslocados de situações de uso práticas.

Apesar disso, o autor explica que os estudantes estão, no ambiente escolar, afastados da maioria das atividades que nos envolvem, assim o objetivo maior dos estudantes está voltado à escolarização. As atividades envolvendo a escrita são, na maioria das vezes, destinadas à aprovação ou à reprovação dos alunos, ou seja, produções que serão avaliadas pelo professor ou outro avaliar externo. É por isso que "as tarefas de escrita, muitas vezes, servem apenas para treinar capacidades de escrita em vez de dedicar-se a um interesse substantivo em termos de conteúdo ou de ação" (BAZERMAN, 2015, p. 107). Mesmo as produções escritas com objetivos reais, como uma carta de reclamação, são simulações, uma vez que não fazem parte de uma situação e necessidade.

Além disso, os estudantes estão sempre presos em uma primeira fase da escrita. Identificamos o problema e, por meio da escrita, agimos sobre ele. $\mathrm{Na}$ vida real, um e-mail de reclamação receberá uma réplica e, por vezes, haverá uma tréplica. Dessa forma, é possível compreender como as produções escritas inserem-se nas atividades reais. Bazerman (2015, p. 107) salienta que isso não acontece na escola já que o aluno "está sempre em fase de aquecimento, tentando fazer algo acontecer". O objetivo da escrita escolar é, portanto, a avaliação. Apesar dessa questão, o exercício da produção textual é essencial durante o período escolar uma vez que ele culmina, invariavelmente, em uma prova de vestibular ou, até mesmo, na prova de redação exigida para assumir um posto de trabalho. Dessa forma, o papel do professor, especialmente frente a estudantes do ensino médio, é tornar a atividade escrita mais significativa ao relacioná-la com situações reais.

A prova de redação do Enem, por sua vez, está inserida em uma atividade real que tem como objetivo, hoje, ser a porta de entrada de muitos jovens no universo universitário. O Enem foi criado em 1998 pelo Instituto Nacional de Estudos e Pesquisas Educacionais Anísio Teixeira (INEP). A ideia inicial centrava-se na possibilidade de, por meio de como um exame individual e voluntário, colher dados que pudessem trazer à tona o resultado palpável de anos de estudos dos alunos concluintes do ensino médio. O objetivo, pois, era avaliar, a partir de competências e habilidades, o conhecimento geral dos alunos. No período de 1998 
a 2008, o Exame foi realizado uma vez por ano com uma prova de 63 questões interdisciplinares. O Enem, durante essa primeira etapa, "se prestava, principalmente, a oferecer uma referência de autoavaliação para os participantes, embora algumas instituições já o utilizassem como instrumento de seleção para ingresso no Ensino Superior" (BRASIL, 2013, p. 12). Com o lançamento do Programa Universidade para Todos (ProUni), em 2004, o ingresso no Ensino Superior realizado pelo Enem foi intensificado. E, em 2009, ocorreu uma reformulação metodológica do Exame com o objetivo de consolidar a sua utilização como forma de seleção unificada nos processos de acesso à educação superior. A partir dessa data, o Exame passou a adotar quatro provas -Ciências da Natureza e suas Tecnologias; Ciências Humanas e suas Tecnologias; Linguagens, Códigos e suas Tecnologias; Matemática e suas Tecnologias -, realizadas em dois dias, cada uma com 45 questões objetivas, totalizando 180 questões, e uma produção escrita do candidato.

A história do exame nos mostra que ele é, de fato, uma atividade real. Bazerman (2015) afirma que as instituições que permeiam o nosso mundo, como o INEP, criam gêneros de comunicação para realizarem suas atividades. Por exemplo, a Receita Federal no Brasil criou um programa especializado para produzirmos a declaração do imposto de renda. Essa declaração pode ser compreendida como um gênero produzido para auxiliar a atividade desenvolvida pela Receita Federal. A redação do Enem, e a sua própria proposta, também são gêneros criados para a tarefa de avaliar nacionalmente a população em seus últimos anos de educação básica.

Ainda que consideremos a artificialidade natural de uma avaliação nacional e escolar, a intencionalidade que sustenta a prova é retórica, pois cria uma mensagem com o objetivo de alcançar um determinado fim e levar um auditório a praticar uma ação definida. A proposta de redação deseja traçar um conjunto de limitações e restrições, como o tema e o gênero da redação a ser produzida, para conseguir avaliar o autor desse texto com base em critérios pré-estabelecidos. Há uma expectativa sobre o texto do aluno, ou seja, acaso sejam seguidas todas as regras ali presentes, o aluno-autor será visto como apto a receber uma nota maior e, consequentemente, a disputar uma vaga no ensino superior. Por isso, a prova de redação é a apresentação de um problema retórico que oferece uma questão também retórica a ser resolvida, um auditório delimitado e um conjunto de limitações e restrições que especificam o contexto. No plano da ação retórica, o auditório, diante da questão proposta, transfor- 
ma-se imediatamente em orador. A partir da leitura de seus componentes, portanto, é possível traçar o que o conjunto de limitações e restrições, que serão o próprio contexto do discurso a ser elaborado pelos alunos, nos ensina sobre os papéis de cada um dos envolvidos nessa situação.

É possível, então, basear-se nesse fato para tornar a experiência da escrita escolar mais significativa ao fazer com que o aluno compreenda as motivações envolvidas nessa avaliação. Analisar a proposta de redação do Enem, por meio de uma leitura retórica, é uma forma de tornar-se mais familiarizado com a atividade da prova em si. Compreender os avaliadores, os alunos e o tipo de discurso esperados torna-se uma forma de dotar a produção escrita em sala de aula relevante e inserir esse discurso em um diálogo entre os textos. A produção textual, assim, não seria mais um aquecimento, mas um diálogo entre produções que culmina na realização da proposta de redação do Enem.

\title{
Leitura: prova de redação
}

A prova de redação do Enem estrutura-se da seguinte forma: instruções para a redação, textos motivadores e proposta de redação.

As instruções, apodíticas, da prova do Enem de 2009 e 2010 eram as seguintes:

\author{
Instruções \\ Seu texto tem que ser escrito à tinta, na folha própria. \\ Desenvolva seu texto em prosa: \\ não redija narração, nem poema. \\ O texto com até 7 (sete) linhas \\ escritas será considerado em branco. \\ O texto deve ter, no máximo, 30 linhas. \\ O rascunho da redação deve ser feito no \\ espaço apropriado. (INEP, 2009, p. 2).
}

No total, compreendem cinco itens que delimitam a extensão do texto, o lugar destinado para o texto final e para o rascunho e o tipo do texto (prosa). É relevante notar que a prova de redação durante esses anos dialogava diretamente com o seu auditório, o aluno, ao realizar marcações textuais como o uso dos pronomes "seu".

As instruções da prova de 2011 já apresentam algumas alterações, mas a presença de "deve" ainda é preponderante: 
Instruções

O rascunho da redação deve ser feito no espaço apropriado.

$\mathrm{O}$ texto definitivo deve ser escrito à tinta, na folha própria, em até 30 linhas.

A redação com até 7 (sete) linhas escritas será considerada "insuficiente" e receberá nota zero.

A redação que fugir ao tema ou que não atender ao tipo

dissertativo-argumentativo receberá nota zero.

A redação que apresentar cópia dos textos da Proposta de Redação ou do Caderno de Questões terá o número de linhas copiadas desconsiderados para efeito de correção. (INEP, 2011, p. 2).

A partir dessas instruções é possível compreender que a prova do Enem passa a apresentar um estilo mais formal. Não há mais o diálogo explícito entre orador (avaliador) e auditório (estudante). O estilo mais formal e neutro adotado pelas instruções já é uma indicação do estilo do discurso esperado pela avaliação.

Percebe-se também que não é mais suficiente apenas elaborar um texto em prosa, conforme as provas de 2009 e 2010, o discurso do aluno deve atender ao tipo dissertativo-argumentativo. Há, portanto, uma delimitação maior quanto ao gênero esperado desse texto.

Outra alteração marcante é a explicitação sobre o caráter avaliativo da produção. Até 2010, não havia indicações sobre o critério de avaliação de textos com menos de sete linhas, apesar de ser implícita a sua desconsideração. A partir de 2011, há a delimitação de dois critérios que são pré-requisitos para a correção: textos de até sete linhas escritas e textos que não sejam dissertativos-argumentativos. Qualquer produção que não atenda esses critérios receberá nota zero. Além disso, a prova exige do aluno um caráter de autoria ao definir que cópia de textos, tanto motivadores quanto questões do restante da prova, serão desconsideradas.

Em 2012, é acrescido mais um pré-requisito para a correção do texto:

Instruções

O rascunho da redação deve ser feito no espaço apropriado.

O texto definitivo deve ser escrito à tinta, na folha própria, em até 30 linhas.

A redação com até 7 (sete) linhas escritas será considerada "insuficiente" e receberá nota zero.

A redação que fugir ao tema ou que não atender ao tipo dissertativo-argumentativo receberá nota zero. 
os direitos humanos receberá nota zero.

A redação que apresentar cópia dos textos da Proposta de Redação ou do Caderno de Questões terá o número de linhas copiadas desconsiderados para efeito de correção. (INEP, 2012, p. 2).

É possível perceber que as instruções da prova do Enem dividem-se em instruções propriamente e situações em que o texto será desconsiderado. Com isso em mente, a partir de 2013 as instruções da prova são apresentadas em duas partes distintas:

\section{INSTRUÇÕES PARA A REDAÇÃO}

O rascunho da redação deve ser feito no espaço apropriado.

$\mathrm{O}$ texto definitivo deve ser escrito à tinta, na folha própria, em até 30 linhas.

A redação que apresentar cópia dos textos da Proposta de Redação ou do Caderno de Questões terá o número de linhas copiadas desconsiderado para efeito de correção.

Receberá nota zero, em qualquer das situações expressas a seguir, a redação que:

tiver até 7 (sete) linhas

fugir ao tema ou que não atender ao tipo dissertativo-argumentativo. apresentar proposta de intervenção que desrespeite os direitos humanos.

apresentar parte do texto deliberadamente desconectada do tema proposto. (INEP, 2016b, p. 2).

Farah (2016) avalia que a inclusão do último item das instruções, "apresentar parte do texto deliberadamente desconectada do tema proposto", foi realizada a partir de críticas realizadas pela imprensa sobre a correção da prova, como ter passado despercebido pelos corretores a inclusão de receitas culinárias e um hino de um time de futebol.

É interessante notar que o Enem 2016 foi o primeiro a contar com as instruções para a redação antes dos textos motivadores e da própria proposta de redação. A prova, portanto, assumiu uma formatação diferente dos anos anteriores. Como as instruções apresentam os casos em que a produção de texto terá nota zero, talvez a inversão de diagramação objetive destacar essas informações.

A análise das instruções da prova do Enem de 2009 até 2016 permite algumas observações: em primeiro lugar é possível afirmar que as instruções, ao longo dos anos, passaram por mudanças para que a avaliação do discurso produzido pelo aluno fosse cada vez mais refinada. Apesar de o estudante não saber o tema da prova, é claro o que é esperado da sua produção. É possível garantir, portanto, que as instruções trazem estabilidade 
para o orador. Farah (2016) indica que a estabilidade é essencial para definir o gênero exigido pela prova e que as mudanças realizadas nas instruções corrigiram quaisquer inadequações percebida durante a correção.

Quanto ao tema, desde 2009, foram abordados pelas provas principais, e transcritos com respeito à formatação de publicação para que seja nítida a alteração do destaque, foram:

2009: "O indivíduo frente à ética nacional"

2010: "O Trabalho na Construção da Dignidade Humana"

2011: "Viver em rede no Século XXI: os limites entre o público e o privado"

2012: "O movimento imigratório para o Brasil no século XXI"

2013: "Efeitos da implantação da Lei Seca no Brasil"

2014: "Publicidade infantil em questão no Brasil"

2015: "A persistência da violência contra a mulher na sociedade brasileira"

2016: "Caminhos para combater a intolerância religiosa no Brasil”"

Para Aristóteles (2011, p. 48), a retórica versa sobre todas as questões "sobre as quais deliberamos e a respeito das quais não dispomos de artes ou sistemas que nos guiem". O campo da retórica é o da opinião, da controvérsia, da crença; é o embate das ideias e dos discursos, da dialética (MOSCA, 2001). Nos últimos anos, as provas versavam sobre o combate a intolerância religiosa, a violência contra a mulher, a publicidade infantil, a implantação da Lei Seca e o movimento migratório. Todos esses temas estão sujeitos às contingências da História, do meio social e, sobretudo, das tendências ideológicas em vigência no período em que foram criados. Em função disso, pode-se afirmar que a prova de redação do Enem constitui um problema retórico, já que incita a criação de um discurso retórico a partir de uma questão dialética, uma vez que o debate acerca dos temas 152 propostos e exige a articulação de argumentos acerca de uma opinião 
preferível, mas não matematicamente lógica.

É, no entanto, apenas em 2012, que o enfoque do tema passa a ser explicitamente a sociedade brasileira. Esse recorte chama a atenção pelo contexto nacional da prova. A delimitação da sociedade brasileira como um todo exige que o autor do discurso pense não só na sua cidade ou no seu estado, mas compreenda a questão de forma mais ampla e respeite, inclusive, a extensão territorial do país em que está inserido.

Todos os temas têm a característica predominante de serem atuais e próximos ao cotidiano dos estudantes de forma geral. São temas debatidos pela mídia e, portanto, é dada aos alunos a possibilidade de já terem refletido sobre eles previamente à prova.

Sobre a elaboração da proposta de redação por si, observam-se algumas alterações. Em 2009, lia-se:

Com base na leitura dos textos motivadores e nos conhecimentos construídos ao longo de sua formação, redija texto dissertativo-argumentativo em norma culta escrita da língua portuguesa sobre o tema $\mathbf{O}$ indivíduo frente à ética nacional, apresentando proposta de ação social, que respeite os direitos humanos. Selecione, organize e relacione coerentemente argumentos e fatos para a defesa de seu ponto de vista (INEP, 2009, p. 2).

No ano seguinte, a "proposta de ação social” foi alterada para: "apresentando experiência ou proposta de ação social, que respeite os direitos humanos" (INEP, 2010, p. 2). Em 2011, houve nova alteração quanto ao texto: "apresentando proposta de conscientização social que respeite os direitos humanos" (INEP, 2011, p. 2). Finalmente, em 2012, o texto foi ajustado para: "apresentando proposta de intervenção, que respeite os direitos humanos" (INEP, 2012, p. 2). É possível que a opção do termo "proposta de intervenção" tenha sido possível graças a popularização da prova e, consequentemente, a compreensão dos professores e estudantes das exigências do exame.

\section{Motivação: definindo papéis}

Para a retórica, o orador é o responsável pela produção do discurso. No entanto, pelo caráter avaliatório do Enem, a proposta de redação prevê um orador ideal e avalia os discursos elaborados em vista desse orador ideal.

Em primeiro lugar, o orador precisa redigir o texto "em modalidade 
escrita formal da língua portuguesa". É esperado um orador capaz de produzir um discurso sem desvios da norma padrão de escrita do idioma e com adequação de registro. Já foi mencionado que a escrita das instruções da prova foi adaptada para um estilo formal e neutro, semelhantemente ao da escrita esperada em textos dissertativos de modo geral. Esse estilo é, portanto, esperado também por parte da produção do orador.

De acordo com o documento Redação no Enem 2016, Cartilha do Participante (INEP, 2016), o orador deve ser capaz de escrever um discurso com ausência de marcas de oralidade e de registro informal, com precisão vocabular e com obediência às regras de concordância nominal e verbal; regência nominal e verbal; pontuação; flexão de nomes e verbos; colocação de pronomes oblíquos (átonos e tônicos); grafia das palavras; e divisão silábica na translineação. A primeira característica do orador ideal é, portanto, ser especialista na modalidade escrita da língua portuguesa.

A próxima exigência do exame é que o discurso seja redigido "com base nos conhecimentos construídos ao longo de sua formação". Assim, o orador ideal deve demonstrar que sabe informações de várias áreas do conhecimento e é capaz de relacionar esse conhecimento com a realidade do mundo. Também é importante que o orador apresente marcas de autoria ao ser solicitado, pela Cartilha do Participante, que "evite recorrer a reflexões previsíveis, que demonstram pouca originalidade no desenvolvimento do tema proposto" (INEP, 2016, p. 16).

O exame também favorece o orador experiente, uma vez que avalia a capacidade do aluno em selecionar, organizar e relacionar, de forma coerente e coesa, argumentos e fatos para a defesa de seu ponto de vista. Nesse sentido, a prova requisita do orador que elabore um discurso eficaz no convencimento do auditório em defesa de um ponto de vista.

Por fim, o orador deve ser um crítico da sociedade em que vive para que seja capaz de elaborar uma "proposta de intervenção que respeite os direitos humanos". É necessário ser um crítico da sociedade no sentido de compreender qual proposta poderia contribuir para o tema da prova e, para além disso, como esta proposta poderia ser aplicada.

Sobre o auditório, a Cartilha do Participante informa que cada texto será lido por dois professores de forma independente, ou seja, um não saberá a nota atribuída pelo outro. Se por acaso houver uma discrepância entre as notas, como uma diferença de cem pontos no total ou oitenta pontos em cada uma das competências, a prova ainda será avaliada por um terceiro professor.

Não é possível desconsiderar a artificialidade de uma avaliação que possua 154 a abrangência do Enem. Assim como em produções textuais realizadas em 
sala de aula, o aluno-orador é encorajado a considerar o seu auditório como universal quando, na verdade, o discurso final é sempre dirigido a um avaliador.

A partir disso, compreende-se que o auditório da prova de redação Enem é um professor de português com nível de conhecimento mediano sobre o tema, o que significa dizer que ele não é um especialista no assunto. Apesar de ser um público altamente versado em questões de linguagem, o tema da prova aborda questões sociais, políticas e culturais. E, mesmo com a preparação minuciosa a que são submetidos, os avaliadores não são absolutamente especialistas em relação ao tema. Ou, ao menos, não o são como em relação às estruturas linguísticas da redação.

Por fim, a prova de redação do Enem espera a produção de um discurso "dissertativo-argumentativo em modalidade escrita formal da língua portuguesa”. É importante que esse discurso defenda uma tese apoiada em argumentos consistentes, de acordo com a Cartilha do Participante.

Por respeitar a estrutura pedagogicamente chamada de dissertativa na escola, compreende-se que esse discurso terá um mínimo de três parágrafos: introdução, desenvolvimento e conclusão. Além disso, o último parágrafo do discurso esperado terá que apresentar uma proposta de intervenção referente a uma questão que envolve a sociedade como um todo.

Dentro da perspectiva retórica, o discurso que será produzido a partir da prova de redação do Enem pertence ao gênero deliberativo, uma vez que determina um procedimento (proposta de intervenção) como aconselhável para solucionar uma questão referente à sociedade. Nesse gênero, é aconselhável que o aluno comprove a sua tese a partir do uso de exemplos. Esse tipo de argumento é compatível como o perfil do orador ideal ao fazer uso de informações compreendidas em diversas áreas de conhecimento. Isso é possível a partir do momento em que os exemplos dos textos deliberativos são baseados em situações passadas, já que é impossível narrar com base em acontecimentos futuros (ARISTÓTELES, 2011).

\section{Considerações finais}

Como futuro cidadão crítico, o aluno deve ser capaz de reconhecer os atos retóricos que o cercam diariamente; deve entender como esses atos objetivam mudar suas atitudes, crenças, opiniões e comportamentos; e deve reconhecer se obtêm sucesso ou fracasso quando atingem um auditório. Enfim, ao assumir um papel de crítico, é necessário que o indivíduo 
descreva, interprete e avalie os discursos que o cercam para compreender o motivo do êxito de cada um e, essencialmente, tenha clara para si a sua finalidade de um discurso público.

Compreender aquilo que é esperado dos alunos durante a prova de redação do Enem e quem é o seu auditório permite uma assimilação do motivo por trás da produção textual. Ainda que artificialmente, simular a motivação da escrita faz com que a produção textual seja inserida em um conceito mais palpável para o estudante e, assim, possa contribuir com seu crescimento. Bazerman (2015) postula que a evolução da escrita tende a acontecer com uma interação que se desenvolve ao longo do tempo, uma vez que "problemas se definem, os papéis de participantes emergem, o trabalho a ser realizado fica mais claro, os fatos da situação e o conhecimento relevante tornam-se salientes" (BAZERMAN, 2015, p. 109). Dessa forma, a leitura retórica da prova de redação em sala de aula por professores e alunos pode ser um instrumento importante para o desenvolvimento da escrita. 


\section{Referências}

ARISTÓTELES. Retórica. Tradução, textos adicionais e notas Edson Bini. São Paulo: EDIPRO, 2011.

BAZERMAN, C. Retórica da ação letrada. São Paulo: Parábola Editorial, 2015.

BRASIL. Exame Nacional do Ensino Médio (Enem): relatório pedagógico 2009-2010/ Instituto Nacional de Estudos e Pesquisas Educacionais Anísio Teixeira. Brasília: O Instituto, 2013.

FARAH, N. E. Proposta de desenvolvimento da produção textual na perspectiva da Educação Linguística - para além do Enem. 2016. Dissertação (Mestrado em Língua Portuguesa). Pontifícia Universidade Católica de São Paulo, São Paulo, 2016.

INEP - Instituto Nacional de Estudos e Pesquisas Educacionais Anísio Teixeira. Exame Nacional do Ensino Médio. Prova de Redação e de Linguagens, Códigos e suas Tecnologias. Prova de Matemática e suas Tecnologias. Brasília: O Instituto, 2009.

INEP - Instituto Nacional de Estudos e Pesquisas Educacionais Anísio Teixeira. Exame Nacional do Ensino Médio. Prova de Redação e de Linguagens, Códigos e suas Tecnologias. Prova de Matemática e suas Tecnologias. Brasília: O Instituto, 2010.

INEP - Instituto Nacional de Estudos e Pesquisas Educacionais Anísio Teixeira. Exame Nacional do Ensino Médio. Prova de Redação e de Linguagens, Códigos e suas Tecnologias. Prova de Matemática e suas Tecnologias. Brasília: O Instituto, 2011.

INEP - Instituto Nacional de Estudos e Pesquisas Educacionais Anísio Teixeira. Exame Nacional do Ensino Médio. Prova de Redação e de Linguagens, Códigos e suas Tecnologias. Prova de Matemática e suas Tecnologias. Brasília: O Instituto, 2012.

INEP - Instituto Nacional de Estudos e Pesquisas Educacionais Anísio Teixeira. Redação no Enem 2016: cartilha do participante. Brasília: O Instituto, 2016.

MOSCA, L. Velhas e Novas Retóricas: Convergências e Desdobramentos. In . (Org.) Retóricas de Ontem e de Hoje. 2 ed. São Paulo: Humanitas, 2001. 
